University of New Hampshire

University of New Hampshire Scholars' Repository

4-2012

\title{
Eclipse Ice Core Accumulation and Stable Isotope Variability as an Indicator of North Pacific Climate
}

\author{
Eric P. Kelsey \\ University of New Hampshire, Durham \\ Cameron P. Wake \\ University of New Hampshire - Main Campus, cameron.wake@unh.edu \\ Kaplan Yalcin \\ University of New Hampshire - Main Campus \\ K Kreutz \\ University of Maine - Main
}

Follow this and additional works at: https://scholars.unh.edu/earthsci_facpub

\section{Recommended Citation}

Kelsey EP, CP Wake, K Yalcin, K Kreutz (2012) Eclipse Ice Core Accumulation and Stable Isotope Variability as an Indicator of North Pacific Climate. J Climate 25(18), 6426-6440.

This Article is brought to you for free and open access by the Earth Sciences at University of New Hampshire Scholars' Repository. It has been accepted for inclusion in Earth Sciences Scholarship by an authorized administrator of University of New Hampshire Scholars' Repository. For more information, please contact Scholarly.Communication@unh.edu. 


\title{
Eclipse Ice Core Accumulation and Stable Isotope Variability as an Indicator of North Pacific Climate
}

\author{
ERic P. Kelsey AND CAMERon P. WAKe \\ Earth Systems Research Center, Institute for the Study of Earth, Oceans and Space, University of New \\ Hampshire, Durham, New Hampshire \\ KAPLAN YALCIN \\ Department of Geosciences, Oregon State University, Corvallis, Oregon \\ KARL KREUTZ \\ Climate Change Institute, and Department of Earth Sciences, University of Maine, Orono, Maine
}

(Manuscript received 12 July 2011, in final form 9 March 2012)

\begin{abstract}
The high accumulation rate and negligible amount of melt at Eclipse Icefield (3017 m) in the Saint Elias Range of Yukon, Canada, allows for the preservation of a high-resolution isotopic and glaciochemical records valuable for reconstruction of climatic variables. Each of the three Eclipse ice cores have a well-constrained depth-age scale with dozens of reference horizons over the twentieth century that permits an exceptional level of confidence in the results of the current calibration exercise. Stacked time series of accumulation and stable isotopes were divided into cold and warm seasons and seasons of extreme high and extreme low accumulation and stable isotope values (eight groups). For each group, season-averaged composites of 500-hPa geopotential height grids, and the individual seasons that constitute them, were analyzed to elucidate common anomalous flow patterns.

This analysis shows that the most fractionated isotopes and lowest accumulation cold seasons reflect a more zonal height pattern in the North Pacific associated with negative Pacific-North American (PNA) and Pacific decadal oscillation (PDO) indices. Conversely, the least fractionated isotopes and highest accumulation cold seasons are associated with a positive PNA pattern. Although only a maximum of approximately $20 \%$ of the total number of accumulation and stable isotope seasons exhibit a relatively consistent relationship with 500-hPa geopotential height patterns, these results support the hypothesis that the most extreme accumulation and extreme isotope cold-season values in the Saint Elias Mountains are related to consistent atmospheric circulation and oceanic sea surface temperature patterns.
\end{abstract}

\section{Introduction}

Several Northern Hemisphere climate proxy records (e.g., ice cores, sediment cores, tree rings) have been calibrated using modern instrumental records with the goal of reconstructing past climate. An accurate calibration is critically dependent on careful and proper dating of the climate proxy record. Dating errors on the order of just 1 or 2 years can lead to an erroneous calibration and

Corresponding author address: Eric P. Kelsey, 8 College Rd., Morse Hall, Earth Systems Research Center, Institute for the Study of Earth, Oceans and Space, University of New Hampshire, Durham, NH 03824.

E-mail: ekelsey@gust.sr.unh.edu a misleading reconstruction of past climate prior to the calibration period (e.g., Schmutz et al. 2000; Cook et al. 2002). The aggregation of multiple well-dated climate proxies can be used to reconstruct climate variability with increased confidence (White et al. 1997; Crowley and Lowery 2000; Mann 2002; Mann et al. 2008).

Glaciochemical and snow accumulation records developed from ice cores recovered from glaciers around the North Atlantic have been calibrated with historical meteorological data and regional pressure patterns. For example, White et al. (1997) found a significant correlation between the stacked Greenland Ice Sheet Project 2 (GISP2) and Greenland Ice Core Project (GRIP) isotope records and the North Atlantic Oscillation (NAO), a climate index representing the sea level pressure (SLP) 
difference between Iceland and the Azores and other meteorological and climatic variables. Meeker and Mayewski (2002) found a strong relationship in the GISP2 ice core between the concentrations of sea salt $\left[\mathrm{Na}^{+}\right]$and non-sea-salt $\left[\mathrm{K}^{+}\right]$and the amplitude of prominent Northern Hemisphere SLP centers (Icelandic low, Azores high, Siberian high, and Southeast Asian low). Additionally, Cook et al. (2002) used a large set of tree-ring width data to reconstruct the NAO to A.D. 1400 and highlighted the importance of proper proxy calibration.

Conversely, fewer climate reconstructions have been performed from proxy records recovered from the North Pacific region (e.g., D'Arrigo et al. 1999; Crowley and Lowery 2000; Biondi et al. 2001; Mann 2002, Mann et al. 2008). The first ice core record from northwestern North America was recovered in 1980 from the high-elevation location of Mount Logan, Saint Elias Mountains, southwestern Yukon, Canada (Holdsworth et al. 1992). The core was extracted from the Northwest Col of the summit plateau at an elevation of $5340 \mathrm{~m}$ (nearly $500 \mathrm{hPa}$ ). Its oxygen isotope record yielded very low correlations with regional station temperature and precipitation due to the distinctly different boundary layer air mass sampled by low-elevation stations (Holdsworth et al. 1991, 1992; Holdsworth and Krouse 2002). However, accumulation at this high-elevation core location exhibits a strong correlation with the distant El Niño-Southern Oscillation (ENSO) through atmospheric teleconnections (Moore et al. 2002, 2003). Rupper et al. (2004) demonstrated a nonlinear connection between Mt. Logan accumulation and midtropospheric circulation, with only high accumulation years associated with a consistent positive PNA pattern. The switch from an antiphase to in-phase relationship around 1890 between the Mt. Logan accumulation and Niño-3.4 SST suggests other undetermined forcings modulate snow accumulation and regional climate (Moore et al. 2001).

Recently, several new ice cores have been recovered from Mt. Logan and surrounding regions, including a new core from Mt. Logan at Prospector-Russell Col (PRCol; 5340 m; Fisher et al. 2004; Osterberg et al. 2008), Bona-Churchill (4420 m; Urmann 2009), King Col (4135 m; Goto-Azuma et al. 2003), and Eclipse Icefield (3017 m; e.g., Yalcin and Wake 2001; Yalcin et al. 2003, 2006b,c, 2007). Fisher et al. (2004) analyzed stable isotope data from three elevations in southwestern Yukon, (PR Col, Eclipse, and Jellybean Lake) and concluded that isotope fractionation is influenced by the moisture source region. Higher-elevation sites experience a large difference in average $\delta^{18} \mathrm{O}$ in zonal versus meridional flow because its moisture source is several thousand kilometers away and can shift dramatically based on the prevailing atmospheric flow pattern. Fisher et al. (2008) posited that a quasi-periodic millennial-scale oscillation in the $\delta^{18} \mathrm{O}$ and deuterium excess $(d)$ time series are an artifact of oscillating enhanced meridional and zonal North Pacific flow patterns that are responsible for the abrupt drop in values at Mt. Logan around A.D. 1840. Fisher et al. (2004) suggest lower elevation sites (i.e., Eclipse) do not exhibit this shift because their moisture source is more local (i.e., Gulf of Alaska and Bering Sea) and cannot shift substantially. An altitudinal transect of stable isotope measurements of snow indicate Mt. Logan and Eclipse are exposed to different isotopic layers of the troposphere during snowfall events (Holdsworth and Krouse 2002; Holdsworth 2008). Accumulation has a minimal correlation with regional station precipitation at Mt. Logan (Holdsworth et al. 1992; Rupper et al. 2004) and the first ice core drilled at Eclipse (1996; Wake et al. 2002). Analysis of the first Eclipse Icefield core showed that isotopes shared a mere $5 \%-10 \%$ variability with regional station summer temperatures (Wake et al. 2002).

The ability to reconstruct past climate from proxy records depends fundamentally on the development of an accurate depth-age scale (e.g., Dansgaard et al. 1989; Alley et al. 1993), especially for the calibration period. Several samples each year are needed for precise dating of firn and ice cores using $\delta^{18} \mathrm{O}$ seasonal variations to delineate annual layer counting (Hammer et al. 1986). The dating error must be of a smaller magnitude than the temporal scale that is being used for reconstruction in order to build a climate record of high confidence. The high snow accumulation rate $[\sim 1.4$ meters of water equivalent per annum ( $\mathrm{m}$ w.e. $\mathrm{a}^{-1}$ )] measured in three separate ice cores from Eclipse provides an opportunity to develop a highly accurate depth-age relationship that can be used with confidence to quantify the extent to which the accumulation and isotope time series reflect changes in a variety of meteorological parameters. In this study, three ice core accumulation and isotope records from the relatively low elevation $(3017 \mathrm{~m})$ of Eclipse were calibrated with modern instrumental data to determine their potential to reconstruct past precipitation, surface temperature, various climate indices and tropospheric flow patterns. This study improves upon the work of Wake et al. (2002) by using a stack of three ice cores that increases the signal to noise ratio and confidence in the results.

\section{Methodology}

\section{a. Data and methods}

Accumulation and stable isotope time series from three ice core records from the Eclipse Icefield (3017 m) 


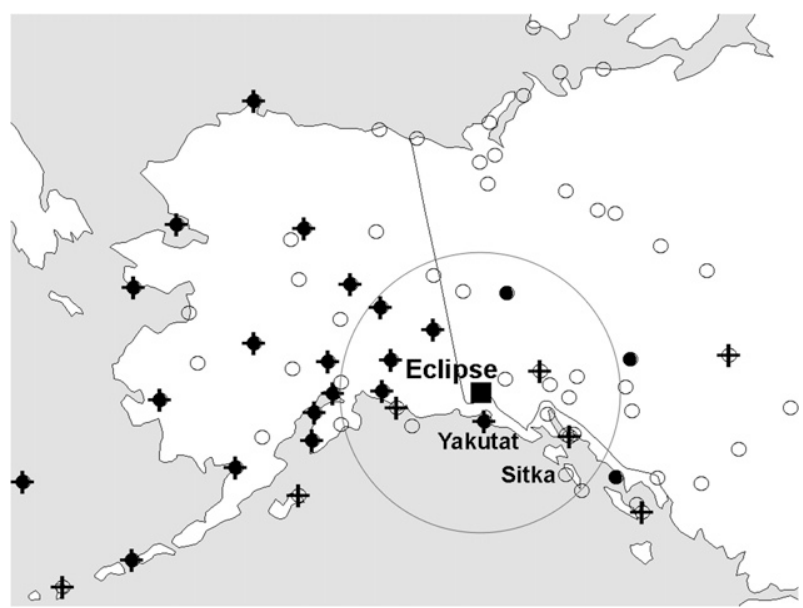

FIG. 1. Map showing locations of all meteorological stations used in this study and the Eclipse Icefield, Yukon, Canada. A subset of stations was used for an empirical orthogonal function analysis of temperature (crosses) and precipitation (filled circles). The large circle marks a 500-km radius around Eclipse. At the scale of this map, the location of the Mt. Logan ice core is effectively the same as Eclipse.

in the Saint Elias Range in Yukon, Canada (Fig. 1), are used in this study. The first core, $160 \mathrm{~m}$ deep, was drilled in the summer of 1996 (Blake et al. 1998), and spans the period 1895-1994. Two other ice cores were drilled $1 \mathrm{~m}$ apart in 2002, approximately $100 \mathrm{~m}$ upflow from the site of core 1 (Yalcin et al. 2006c). All three cores were analyzed continuously at high resolution for isotopes and major ions (Yalcin et al. 2006b). Data records used from core 2 (345 m, A.D. 1000) and core 3 (130 m, A.D. 1910) are 1828-2000 and 1910-2001, respectively. Firn density was measured for each core segment $(\sim 1 \mathrm{~m})$ using bulk mass and volume measurements and accounting for any ice layers, for which density was assumed to be $0.91 \mathrm{~g} \mathrm{~cm}^{-3}$. A high level of confidence in the depth-age relationships developed for all the Eclipse cores is based on the identification of 40 volcanic eruptions using the ice core sulfate record, geochemical fingerprinting of four tephra layers in the ice core using major oxide analysis of individual glass shards, beta activity peaks from atmospheric nuclear weapons testing in 1962 and 1963 and the 1986 Chernobyl accident, and strong seasonal signals in the $\delta^{18} \mathrm{O}$ and $\left[\mathrm{Na}^{+}\right]$time series (Yalcin and Wake 2001; Yalcin et al. 2003, 2006b, 2007). The high accumulation rate significantly diminishes the chances of missing even a low accumulation year. The dating errors on these high resolution ice cores are estimated at $\pm 1 \mathrm{yr}$ for the nineteenth and twentieth centuries (Yalcin et al. 2007).

Monthly values of station cumulative precipitation and average temperature were obtained from the National Climatic Data Center's Global Historical Climate
Network (GHCN) (http://www.ncdc.noaa.gov/ghcnm/) to test how well Eclipse records represent regional low elevation precipitation and temperature. All stations in Alaska and northwest of $55^{\circ} \mathrm{N}$ and $120^{\circ} \mathrm{W}$ in Canada were selected from the $\mathrm{GHCN}$ and retained for the study if the station had at least 30 years of data and at least 8 months of data per year. Of the 142 total stations in this domain, 75 (72) stations met the data quality requisite and were retained for their temperature (precipitation) records. Missing monthly data were filled by a linear regression analysis from stations that exhibited a coefficient of determination of at least 0.5 with the station of missing data. If no station was available to fill in the data, the average of that respective month from all other years in that station's record were used.

The dominant modes of variability of the station annual and seasonal temperature and precipitation time series were calculated using an empirical orthogonal function (EOF) analysis (e.g., Wilks 2006). This statistical analysis calculates the modes responsible for the common variability exhibited by a group of vector data, which in this case are time series. The first eigenmode represents the highest variability in the dataset, with each successive eigenmode representing the most variability remaining in the dataset and being orthogonal to all other eigenmodes. A subset of stations was chosen based on completeness ( $\geq 95 \%$ for temperature, $\geq 85 \%$ for precipitation) for the 1942-2001 time frame: 26 stations for temperature and 22 stations for precipitation. These eigenmodes of temperature and precipitation were analyzed to determine dominant modes of variability that the Eclipse records share. Hereafter, "precipitation" refers to that from the stations and "accumulation" refers to snowfall preserved at Eclipse.

The high accumulation rate of the Eclipse site allows for seasonal analysis. Seasonal resolution is useful to investigate how different seasonal atmospheric circulation patterns impact the ice core record. Annual (JanuaryDecember), cold-season (October-March; labeled by the year in which it ends), and warm-season (AprilSeptember) ice core accumulation (Fig. 2) and isotope values (Fig. 3) were calculated. The seasons were defined by identifying the most (least) negative isotope value and assigning it a date of 1 January (1 July), and then assuming a constant accumulation rate between these points. The lack of real-time, year-round station measurements at Eclipse precludes knowledge of when the typical timing of isotope maxima and minima occur and the 6-month seasons used should help to minimize effects of seasonal dating errors. The water equivalent depth of each season was calculated. Each of the three ice core accumulation time series, and one stacked (the average of the accumulation of all three cores) time 

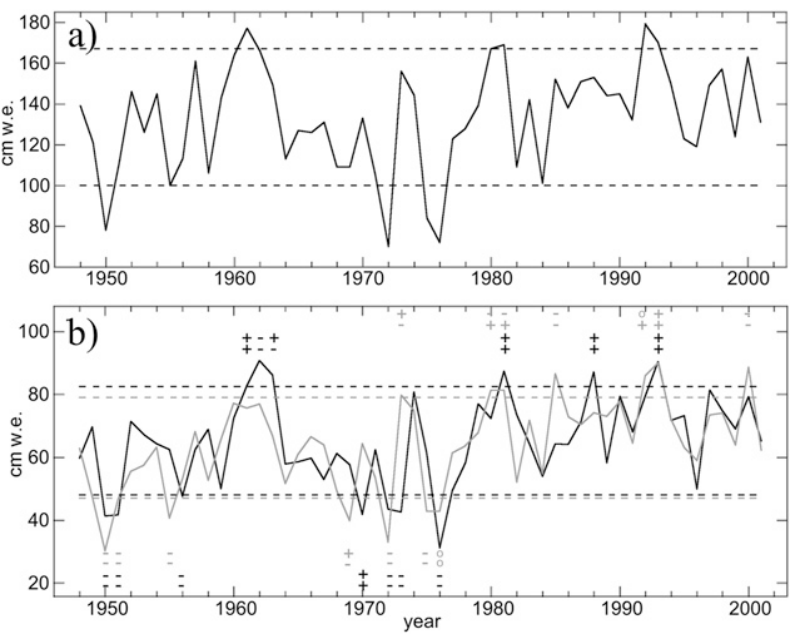

FIG. 2. Time series of stacked (a) annual and (b) cold- (OctoberMarch; black) and warm-season (April-September; gray) ice core water equivalent accumulation. The horizontal dashed lines indicate the threshold used to indicate the extreme (a) years, (b) cold seasons (black), and warm seasons (gray). The pairs of plus, neutral (circle), or negative signs indicate the predominant sign of the (top) PNA index and (bottom) PDO for the extreme cold (black) and warm (gray) seasons.

series was compared with regional station precipitation. A similar analysis was performed among the $\delta^{18} \mathrm{O}$ time series and regional station temperature. A full $\delta^{18} \mathrm{O}$ time series was not obtained from core 2 and $\delta \mathrm{D}$ was used instead. A stacked core for $\delta^{18} \mathrm{O}$ and $\delta \mathrm{D}$ was computed by averaging their standardized values (Fig. 3). Because of the different ages of the tops of the three cores, the stacked core consists of the mean of cores 2 and 3 for 1996-2000, and 2001 is the value of core 3 . Annual correlations of cores 1 and 2 with core 3 were 0.71 and 0.65 , respectively, and ranged between 0.40 and 0.58 for the seasons.

Geopotential height data at $500 \mathrm{hPa}$ comes from the National Centers for Environmental Prediction (NCEP)National Center for Atmospheric Research (NCAR) reanalysis $2.5^{\circ} \times 2.5^{\circ}$ horizontal-resolution dataset (Kalnay et al. 1996). The time frame analyzed is that for which the ice cores and the reanalysis dataset overlap, 1948-2001.

A primary objective of this research is to determine whether the seasonal Eclipse records are associated with any atmospheric patterns, what the patterns are, and to quantify this relationship. To do so, the seasonal ice core values were initially grouped into terciles by partitioning them by \pm 1 standard deviation to compare atmospheric circulation differences between the high and low seasons, as was done similarly with nitrate and sulfate for core 1 by Wake et al. (2002). However, composites of 500-hPa geopotential height for each tercile too closely resembled climatology because of multiple anomaly
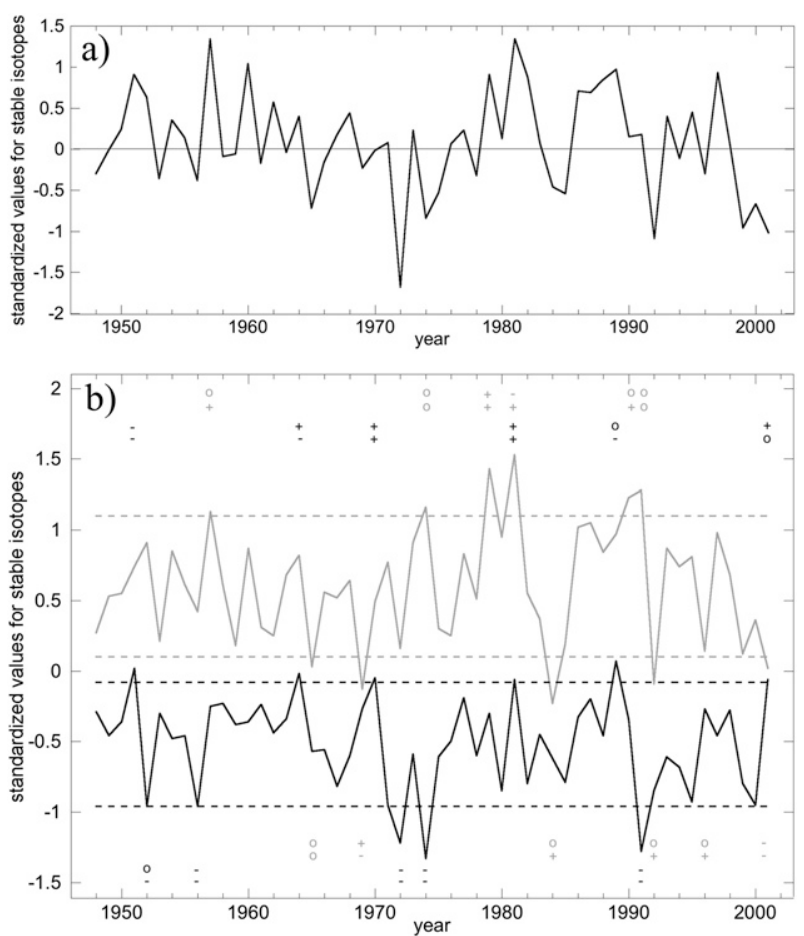

FIG. 3. Time series of mean (a) annual and (b) warm- (gray) and cold-season (black) stacked core standardized isotopes. In (b) the pairs of plus, neutral (circles), or negative signs indicate the predominant sign of the (top) PNA index and (bottom) PDO for the extreme cold (black) and warm (gray) seasons.

patterns offsetting each other. Therefore, we defined groups of seasons by identifying a step function in the ranking (i.e., from high to low) of the seasonal values in the ice core records. A step function, where the extreme seasons have values that are significantly higher/lower than the middle group, is apparent in all but three of the eight groupings (most fractionated warm, least fractionated cold, and low accumulation warm seasons). For these three groupings, the highest and lowest 5 years $(10 \%)$ were used. This analysis was performed for eight $\left(2^{3}\right)$ groups: the highest and lowest values of accumulation and isotopes for the cold and warm season. The groups consisted of between four and six seasons (of the highest or lowest proxy values). For each group, composites of 500-hPa geopotential height anomalies were produced to elucidate common patterns for each group.

Statistical significance shown for the 500-hPa geopotential height anomaly composites was calculated using resampling theory (Wilks 2006). Also described as a Monte Carlo technique, this test uses only real data and is used widely in meteorology and paleoclimatology studies (e.g., Gershunov and Barnett 1998; Thompson and Wallace 2001; Moore et al. 2002; Kaufman et al. 2009). Artificial composites of the same number of seasons 
were computed by randomly selecting seasons without replacement from the NCEP-NCAR reanalysis dataset. Then, the anomaly values in the real composites were compared grid point by grid point with the distribution of values generated from a set of $10^{4}$ artificial composites. Real anomaly values were considered statistically significant at the $95 \%$ level if they fell outside the 5th and 95 th percentiles.

Monthly-averaged climate indices used for correlations with the core and station data include the Pacific decadal oscillation (PDO; Zhang et al. 1997; Mantua et al. 1997), Multivariate ENSO Index (MEI, Wolter and Timlin 1993, 1998), Niño-3.4 (Trenberth 1997), PacificNorth American pattern (PNA, Wallace and Gutzler 1981), and Arctic Oscillation (AO, Higgins et al. 2000). These indices were chosen because of their direct or indirect association with wind, temperature, and precipitation variability around Eclipse that may leave a robust proxy signal.

The PDO index describes a multidecadal ( $~ 50-60-\mathrm{yr}$ period) cycle in the SST anomalies in the Pacific basin (similar to ENSO). The positive phase exhibits warm anomalies in the central equatorial Pacific and along the western coast of North America to coastal Alaska. Cool SST anomalies stretch eastward from the Asian coast across the northern midlatitudes. These anomalies act to increase the SST gradient south of Alaska and increase low-level baroclinicity through differential heat and moisture fluxes with the atmosphere. The negative PDO phase is the opposite SST pattern and decreases the magnitude of the SST gradient.

The PNA index describes a dominant mode of variability in the atmospheric circulation in the Northern Hemisphere extratropics, most notably during the cold season (Barnston and Livezey 1987). The positive phase represents a wave pattern of above and below average 500-hPa geopotential heights that enhances the climatological midlatitude wave pattern. Above average heights are found in the tropical central Pacific and over the Intermountain West of North America. Below average heights are located in the region of the Aleutian low and southeastern United States. The height anomalies of the negative phase of the PNA have the opposite sign. Monthly values generally reflect recurring atmospheric patterns on shorter temporal scales in most cases, as opposed to offsetting periods of opposite flow patterns (Vega et al. 1995). Through oceanic-atmospheric coupling, the phase of the PDO (SST pattern) is frequently in phase with the PNA (atmospheric pattern) during the cold season $(r=0.71)$ when the PNA is active (Barnston and Livezey 1987). An annual correlation results in $r=0.64$ and during the warm season $r=0.38$.
The MEI is a multivariate measure of ENSO that incorporates air and sea surface temperatures, wind, mean sea level pressure, and cloudiness over the tropical $\mathrm{Pa}$ cific. The behavior of tropical meteorology can result in strongly influenced midlatitude weather through various atmospheric patterns, including the pattern described as the PNA, and modulate atmospheric responses to other forcings (Yu and Zwiers 2007).

The AO pattern represents the leading eigenmode of the $1000-\mathrm{hPa}$ geopotential heights north of $20^{\circ} \mathrm{N}$ for 1979-2000 and contains most of the variability of the NAO. During a positive phase AO, negative anomalies cover most of the Arctic Ocean and across Greenland and Iceland. Positive anomalies flank in the Aleutian low region and in the eastern Atlantic midlatitudes. The anomaly pattern has opposite signs during a negative phase AO.

\section{b. Stacked eclipse core}

Averaging multiple well-dated ice core time series provides a climate proxy that maximizes signal-to-noise ratios (Fisher and Koerner 1994; Fisher et al. 1996; White et al. 1997; Kreutz et al. 2004) and should provide an improved climate signal compared with the record available from a single core. The mathematical process of averaging significantly reduces high-frequency noise that arises from spatial variability during deposition and postdepositional processes (e.g., melt, sublimation, and wind scour; Fisher and Koerner 1994) and is more effective than averaging the time series over multiple year periods (Fisher et al. 1996). Averaging over multiple years would also prevent a seasonal or annual calibration. Although slight smoothing of the data can occur, stacking of data from multiple cores provides a more robust record of the true climate signal because of the increased number of records used. This approach depends on the accuracy of the depth-age relationship for each core as dating errors of even one year will reduce the fidelity of the climate signal in the stacked record.

Stacking was performed on both the annual and seasonal accumulation and isotope time series. The results show that the stacked core retains a strong common signal (Table 1). The first EOF represents the majority of the common accumulation and isotope signal contained in all three cores and accounts for the majority of the variability in all groupings, especially in the accumulation groupings. Likewise, more than half of the variance of the individual cores' time series are represented by the stacked core for all but two time series (both exceptions with core 1).

Our confidence is highest for the stacked core as the best Eclipse paleoclimate record because it utilizes three interpretations of Eclipse climate, maximizes signal 
TABLE 1. The variance explained by the first eigenmode of an EOF analysis performed on the seasonal and annual accumulation and stable isotopes time series from all three Eclipse ice cores. All relationships are positive.

\begin{tabular}{lcccc}
\hline \hline & \multirow{2}{*}{$\begin{array}{c}\text { Total } \\
\text { EOF1 }(\%)\end{array}$} & \multicolumn{3}{c}{ EOF1 variance $(\%)$} \\
\cline { 3 - 5 } & Core 1 & Core 2 & Core 3 \\
\hline Annual accumulation & 77.9 & 74.3 & 81.7 & 77.6 \\
Cold-season accumulation & 65.2 & 64.1 & 74.0 & 57.5 \\
Warm-season accumulation & 72.6 & 70.2 & 76.6 & 71.0 \\
Annual isotopes & 51.1 & 40.5 & 53.9 & 59.0 \\
Cold-season isotopes & 55.9 & 55.6 & 59.1 & 53.1 \\
Warm-season isotopes & 57.2 & 34.9 & 74.0 & 62.6 \\
\hline
\end{tabular}

to noise ratio, and minimizes spatial variability resulting from postdepositional influences (Kreutz et al. 2004). The seasonal variability of isotope ratios and accumulation are greater than the spatial variability measured from four snow pits at Eclipse (Yalcin et al. 2006b) indicating that most variability is a nonlocal signal. The highly constrained depth-age scale for each core dramatically reduces the potential for annual layer dating errors and maximizes the climate signal. For these reasons, we have the most confidence in the stacked core time series and will use it in the remainder of our analyses.

\section{Results}

\section{a. Comparisons with station time series}

The first two station precipitation eigenmodes $\left(\mathrm{E} 1_{p}\right.$ and $\mathrm{E} 2{ }_{p}$ ) reveal two distinct patterns that represent $20.5 \%$ and $14.1 \%$ of the overall variability, respectively, for 1942-2001. The $\mathrm{E} 1$, shows positive variability in precipitation at western and southwestern, continental, lowelevation stations in Alaska (Fig. 4a). At least $40 \%$ of the variability is explained at 5 of the 21 stations. $\mathrm{E} 1_{p}$ has a correlation coefficient of $r=0.38$ (14\% variability explained) with the stacked core, indicating the strongest regional mode of precipitation has a strong influence on Eclipse accumulation. E2 2 shows a south coastal precipitation pattern (Fig. 4b) and shares at least $22 \%$ of precipitation variability in three south coastal stations and two eastern inland locations. Yakutat, Alaska (the closest station to Eclipse), exhibited the highest value with $54 \%$ of variability shared. The correlation coefficient between $\mathrm{E} 2{ }_{p}$ and core accumulation is $r=0.21$.

Variability in temperature is dominated by the first eigenmode $\left(\mathrm{E} 1_{t}\right)$ with $61 \%$ variance shared (Fig. 5). This variance is much higher than those for precipitation and reflects the differing spatial scale of variability of each phenomenon. All 26 stations exhibited direct variance of at least $27 \%$. Central and southern Alaskan stations
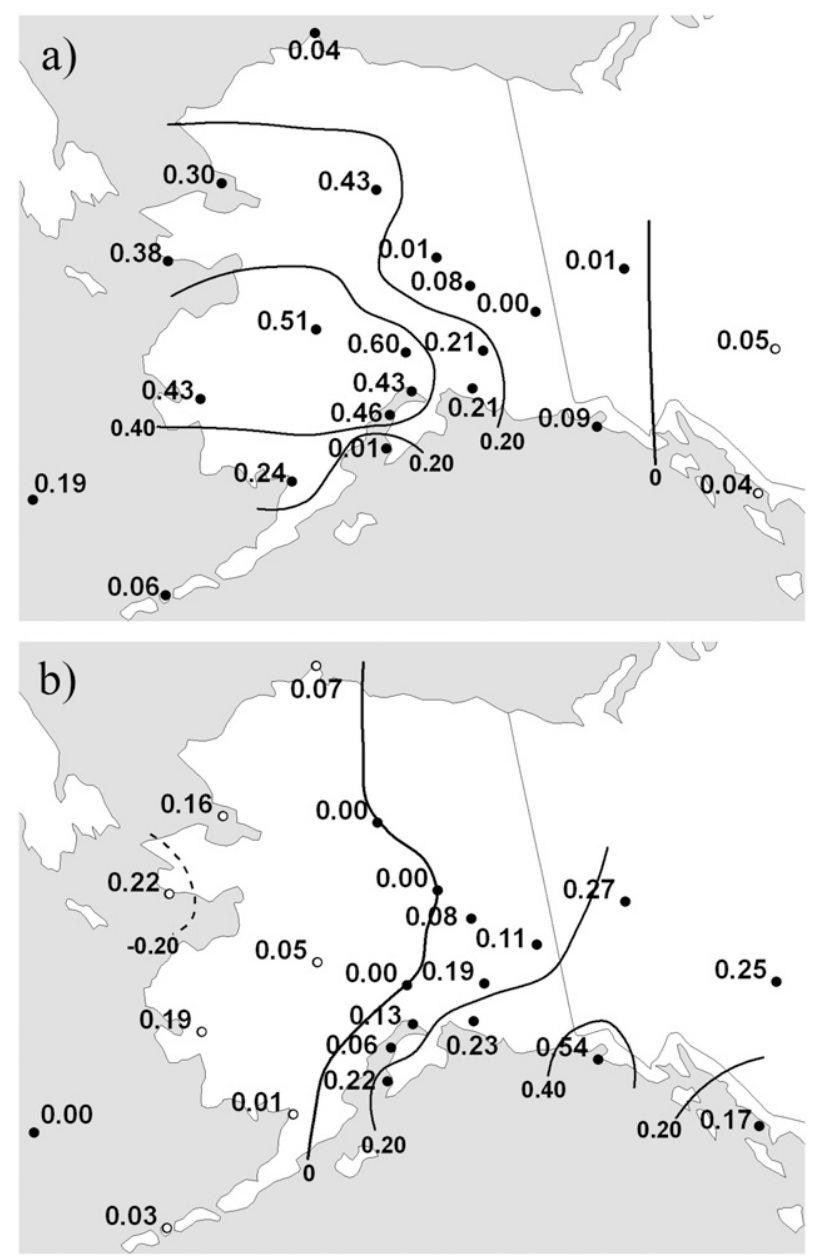

FIG. 4. Proportion of variability explained $r^{2}$ associated with the (a) first and (b) second eigenmode of 22 station annual precipitation records for 1942-2001. Open circles indicate an inverse relationship.

showed the highest amount of variance explained with six stations over $80 \%$ and 20 stations with at least $50 \%$. Stations with a strong marine influence (along the coasts or on islands) generally had the lowest variance explained by this first eigenmode. The correlation between the Eclipse stable isotopes and $\mathrm{E} 1_{\mathrm{t}}$ was $r=0.42$ (18\% variability explained), which suggests that isotopes vary with the type of air mass traversing the region. Analysis of $\mathrm{E} 1_{t}$ suggests that temperature across the entire region is likely regulated by transient largescale air masses, which are modified by the SST at coastal locations.

Cold-season precipitation in Sitka, Alaska, a coastal station close to the Eclipse Icefield, correlated best with Eclipse accumulation $(r=0.54)$. Several other stations correlated above $r=0.30$ (at $p=0.05$; Table 2). On average, the seasonal and annual $r$ values are consistent in magnitude between seasons and variables. More 


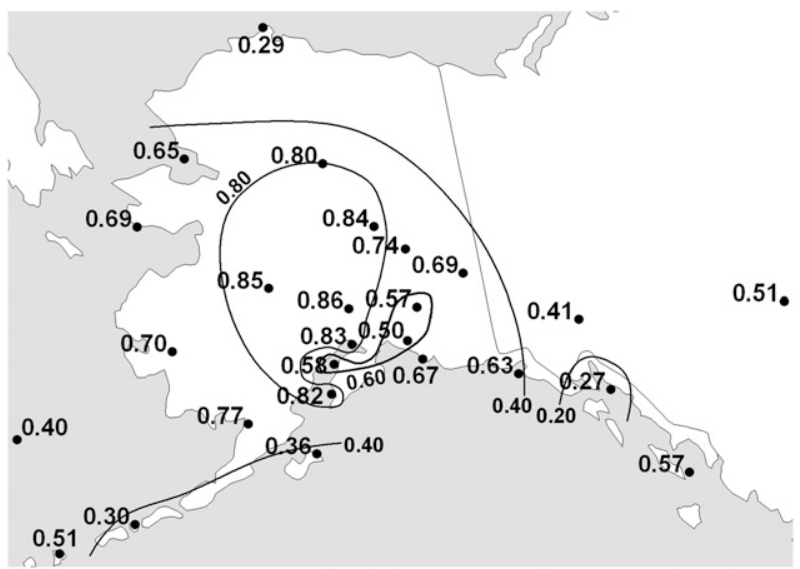

FIG. 5. As in Fig. 4, but for the first eigenmode of 26 station annual temperature records.

stations had $r \geq 0.30$ for temperature than for precipitation, which is consistent with large air masses dominating temperature variability and the high spatiotemporal variability of precipitation. Most of the stations in Table 2 are located in the regions of highest variance as defined by the eigenmodes in Figs. 4 and 5, inferring that Eclipse ice core records preserve a regional temperature and precipitation signal.

The longer annual time frame yielded many higher correlations and more total correlations greater than or equal to 0.30 (Table 2 ). The high variability of precipitation in time and space, differences resulting from topographic influences and small errors in the delineation of seasons in the ice core depth-age scales likely account for this difference. This suggests that a time interval of less than a year may be too short to allow meso- and regional-scale precipitation mechanisms to consistently homogenize precipitation receipts in northwestern North America.

\section{b. Ice core accumulation-seasonal 500-hPa geopotential height patterns}

The climatological mean 500-hPa geopotential heights for each season are shown in Fig. 6. The cold season exhibits a mean trough along the eastern Asian coast associated with this cyclogenic coastal region. The tight geopotential height gradient around the base of the trough relaxes to the east, and splits in the eastern Pacific with the northern branch rounding a ridge just inland of the western coast of North America. Eclipse Icefield lies in the mean southwest flow on the upstream side of this ridge. In the warm season, the mean trough and associated tight geopotential height gradient shift eastward to the longitude of the Bering Sea (largest longitudinal band of cold water in the North Pacific). Again, the Eclipse
Icefield is in the mean southwest flow on the upstream side of the western North American ridge anchored by the Rocky Mountains in the same location as the cold season.

The most consistent pattern that high accumulation cold seasons $(1962,1963,1981,1988,1993)$ display is positive $500-\mathrm{hPa}$ geopotential height anomalies in western North America statistically significant at $p=0.05$ (Fig. 7a). The composite mean height anomalies imply enhanced meridional flow between positive anomalies $(>30 \mathrm{~m})$ in western North America and negative anomalies $(<-20 \mathrm{~m})$ in the central North Pacific. Statistically significant negative anomalies $(<-40 \mathrm{~m})$ covered the eastern Arctic. Four of the five cold seasons exhibited this positive PNA pattern with the exception being 1962. The 1962 cold season had a reversal of the signs of the anomaly couplet, a negative PNA pattern, implying less amplified (i.e., more zonal) flow.

Atmospheric circulation associated with the top 4 years of high accumulation in the warm season $(1985,1992$, 1993, 2000) are highly variable, but their average shows positive $500-\mathrm{hPa}$ geopotential height anomalies in the western North American ridge, the adjacent northeastern Pacific, and southeastern Siberia (Fig. 7b). All four warm seasons had negative or neutral anomalies in the central Pacific on the southern, upstream side of the mean trough indicating the trough reached farther south and sharpened. An important commonality of all four warm seasons is a sharpening of the mean Rossby wave in the Pacific, thus implying increased frequency of, and/or stronger, meridional flow bringing moisture to the St. Elias region.

The composite 500-hPa geopotential height pattern of the six cold seasons of lowest accumulation $(1950,1951$, 1970, 1972, 1973, 1976) shows the opposite anomalies within the Pacific Rossby wave (Fig. 7c). Although not statistically significant, the positive central Pacific and negative western North American anomalies imply a flatter wave and zonal flow. Four of the six cold seasons show this signal. Much of the tropics and subtropics around the Northern Hemisphere had statistically significant negative anomalies, and may simply reflect the cooler hemispheric mean temperature of the first half of the period of study.

During the warm season, the lowest six accumulation years $(1950,1955,1969,1972,1975,1976)$ each show different height anomaly patterns. Each warm-season anomaly pattern does not show a well-defined Pacific region pattern of any sort, but most show a flatter Rossby wave amplitude in the northeast Pacific region as implied by the negative composite height anomalies from the Siberian peninsula to the Gulf of Alaska (Fig. 7d). 
TABLE 2. Correlation coefficients between annual- and seasonal-average Eclipse accumulation and station precipitation, and Eclipse isotope ratios and station temperature for data available for any years during the 1842-2001 period. Correlations greater than or equal to 0.30 are shown. All stations have at least 30 years/seasons of data during the period of the stacked core record (1910-2001). All $r$ values are statistically significant at $p=0.05$.

\begin{tabular}{|c|c|c|c|c|c|c|c|c|}
\hline \multirow[b]{2}{*}{ Station } & \multirow[b]{2}{*}{ Lat } & \multirow[b]{2}{*}{ Lon } & \multicolumn{3}{|c|}{ Accumulation-Precipitation } & \multicolumn{3}{|c|}{ Isotopes-Temperature } \\
\hline & & & Cold & Warm & Annual & Cold & Warm & Annual \\
\hline Bettles, AK & 66.92 & -151.52 & & & & 0.35 & 0.35 & 0.40 \\
\hline Kotzebue, AK & 66.87 & -162.63 & & & & & 0.41 & 0.36 \\
\hline Fort Yukon, AK & 66.60 & -145.30 & & 0.42 & 0.37 & & & \\
\hline Norman Wells, NW & 65.28 & -126.80 & 0.32 & & 0.32 & & & 0.32 \\
\hline Nome, AK & 64.50 & -165.43 & & & & & 0.40 & 0.32 \\
\hline Big Delta, AK & 64.00 & -145.73 & & & & & & 0.40 \\
\hline Unalakleet, AK & 63.88 & -160.80 & & & 0.31 & 0.37 & & \\
\hline McKinley Park, AK & 63.70 & -149.00 & & 0.31 & & & & \\
\hline Wrigley, NW & 63.22 & -123.43 & & & & & & 0.34 \\
\hline McGrath, AK & 62.97 & -155.62 & & & & & 0.42 & 0.41 \\
\hline Northway, AK & 62.97 & -141.94 & & & 0.43 & & & 0.37 \\
\hline Talkeetna, AK & 62.30 & -150.10 & & & & & 0.33 & \\
\hline Gulkana, AK & 62.15 & -145.45 & & & 0.36 & & & 0.38 \\
\hline Puntilla, AK & 62.10 & -152.75 & 0.32 & 0.46 & 0.45 & & & 0.49 \\
\hline Matanuska, AK & 61.60 & -149.30 & & & 0.34 & & & \\
\hline Valdez, AK & 61.13 & -146.35 & & & 0.40 & & & \\
\hline Bethel, AK & 60.78 & -161.80 & & & & & 0.42 & 0.33 \\
\hline Haines Junction, YT & 60.77 & -137.58 & & & & 0.46 & & 0.35 \\
\hline Whitehorse, YT & 60.72 & -135.07 & & & & & 0.37 & 0.31 \\
\hline Kenai, AK & 60.57 & -151.25 & 0.35 & & & 0.36 & & 0.44 \\
\hline Carcross, YT & 60.18 & -134.70 & 0.33 & & & & & \\
\hline Teslin, YT & 60.17 & -132.73 & & & & 0.39 & & \\
\hline Seward, AK & 60.12 & -149.45 & & & 0.30 & & & \\
\hline Homer, AK & 59.63 & -151.50 & & & & 0.33 & 0.32 & 0.30 \\
\hline Yakutat, AK & 59.50 & -139.70 & & & 0.31 & & & \\
\hline Haines, AK & 59.23 & -135.43 & & & 0.30 & & & \\
\hline Dease Lake, BC & 58.42 & -130.00 & 0.32 & & 0.34 & 0.47 & 0.32 & 0.41 \\
\hline Juneau aiport, AK & 58.37 & -134.58 & & & 0.38 & & & \\
\hline Annex Creek, AK & 58.32 & -134.10 & & & 0.33 & & & \\
\hline Juneau No.2, AK & 58.30 & -134.40 & 0.32 & & & & & \\
\hline Sitka Magnetic Observatory, AK & 57.10 & -135.30 & 0.42 & & & & & \\
\hline Sitka, AK & 57.07 & -135.35 & 0.54 & & 0.48 & & & \\
\hline Wrangell, AK & 56.48 & -132.37 & & & & & 0.30 & \\
\hline Little Port Walker, AK & 56.39 & -134.66 & & & & 0.35 & & \\
\hline Cold Bay, AK & 55.20 & -162.72 & & & & & & 0.30 \\
\hline
\end{tabular}

\section{c. Ice core stable isotopes-seasonal 500-hPa geopotential height patterns}

The strongest and most consistent 500-hPa geopotential height anomaly signal for seasonal stable isotopes was associated with the most fractionated isotopes during the cold season $(1952,1956,1972,1974,1991 ;$ Fig. 8a). In this grouping, each of the five cold seasons show a greater than 70-m-height anomaly (composite of $>60 \mathrm{~m}$ ) on or just southeast of the International date line-Aleutian Islands crossing and a less than $-40 \mathrm{~m}$ anomaly over western North America. For all five cold seasons, this anomaly pattern was part of an anomaly wave train from the tropical Pacific to the western Atlantic that closely resembles the negative PNA pattern. In effect, the arrangement of these anomalies acted to flatten the climatological Rossby wave pattern in this region and the average seasonal flow was zonal. A weak negative NAO pattern occurred over the North Atlantic.

The six most fractionated isotopes warm seasons (1965, 1969, 1984, 1992, 1996, 2001) exhibited higher variability in the magnitude and shape of the anomalies. All six warm seasons had positive anomalies in the Bering Sea region and negative anomalies to the east, leading to a weaker wave pattern on average (Fig. 8b). The years of least fractionated isotopes in the cold (1951, 1964, 1970, 1981, 1989, 2001) and warm seasons (1957, 1974, 1979, 1981, 1990, 1991) yielded little commonality, respectively, and weak average anomaly patterns (Figs. $8 \mathrm{c}, \mathrm{d})$. The cold-season individual years show strong 

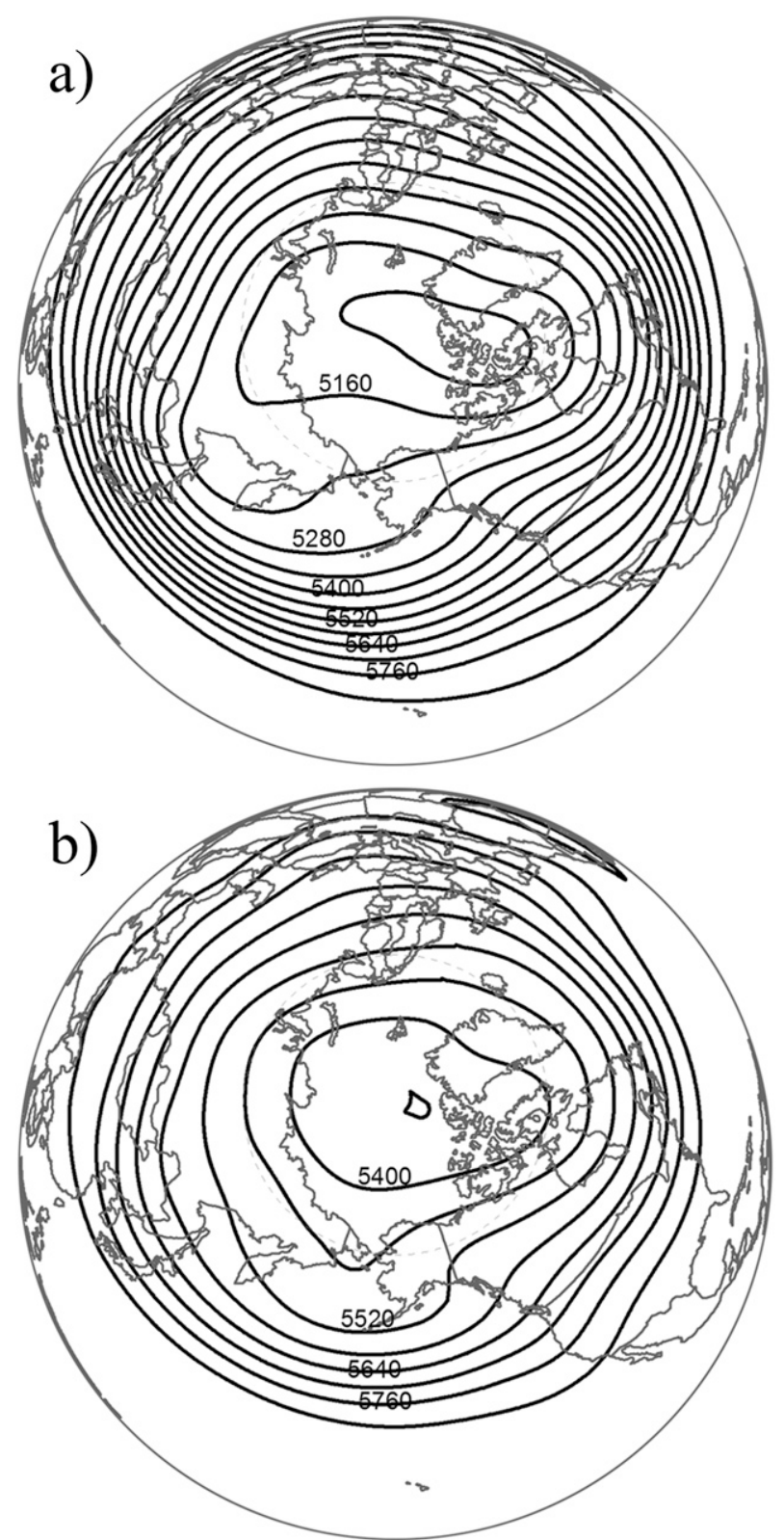

FIG. 6. Climatological 500-hPa geopotential heights for the (a) cold season and (b) warm season.

anomaly patterns, however, no more than two share the same pattern. The warm-season composite contained statistically significant positive height anomalies ( $>20 \mathrm{~m})$, implying warmer temperatures, in Alaska for most warm seasons with little else in common. Although some statistically significant anomalies are shown in the composites composed of highly variable patterns, typically only one or two members are responsible for those anomalies and do not represent a consistent signal.

\section{d. Climate indices}

The strongest correlation occurred between the PDO and warm-season accumulation $(r=0.50$; significant at $p=0.001$ ). Cold season isotopes correlated with the PDO, PNA, and NPI at $r=0.32,0.42$ and -0.32 , respectively (each significant at $p=0.05$ ). All other correlations were statistically insignificant $(p>0.05)$ with $r \leq 0.26$. However, the MEI did correlate strongly at a 1 -yr lag with warm-season accumulation, which may result from the 2-3-yr-long nature of most ENSO events.

Isolating the most extreme seasons reveals strong correspondence with the climate indices. Six and five of the seven cold seasons with the lowest accumulation saw a negative PDO and PNA, respectively (see plus and minus signs in Fig. 2). Conversely, the PDO was positive for four of six and the PNA was positive for five of six of the high accumulation cold seasons. Also, the AO was negative for five of the top six high accumulation cold seasons. The PDO was negative for seven of the eight warm seasons with the lowest accumulation, with the exception being neutral. The PDO was positive for five and the PNA was negative for four of the six high accumulation warm seasons.

The best extreme seasonal correspondence occurred with the eight most fractionated isotopes cold seasons and the PDO-all eight were strongly negative. In fact, the PDO was negative for all but 3 of the 48 months and the PNA was also predominantly negative for six of the eight seasons. For the cold-season least-fractionated isotopes, the $\mathrm{AO}$ was negative for the top 10 seasons except the top season, the PNA was positive for all but the top two seasons, and the PDO was positive for 6 of 10 seasons. Four of the top six least fractionated isotopes warm seasons experienced a positive PDO and the PNA was largely neutral. No preference occurred for any index for the most fractionated isotopes warm seasons. In general, the PDO and PNA were in phase and consistent with each other and the proxies during the cold season and less consistent during the warm season.

\section{e. Tests for robustness and sensitivity}

The fidelity of the stacked core was tested by performing the same season-by-season 500-hPa geopotential height analysis on each of the three cores for accumulation and isotope ratios and comparing them with the stacked core composites. In all cases, extreme proxy values from individual cores do not have a better relationship than the stacked core. In addition, as determined from Table 2, the stacked records of Eclipse accumulation and isotopes reflect a significant portion of lowerelevation station precipitation and temperature variability (several stations with 10\%-29\% shared variance). 

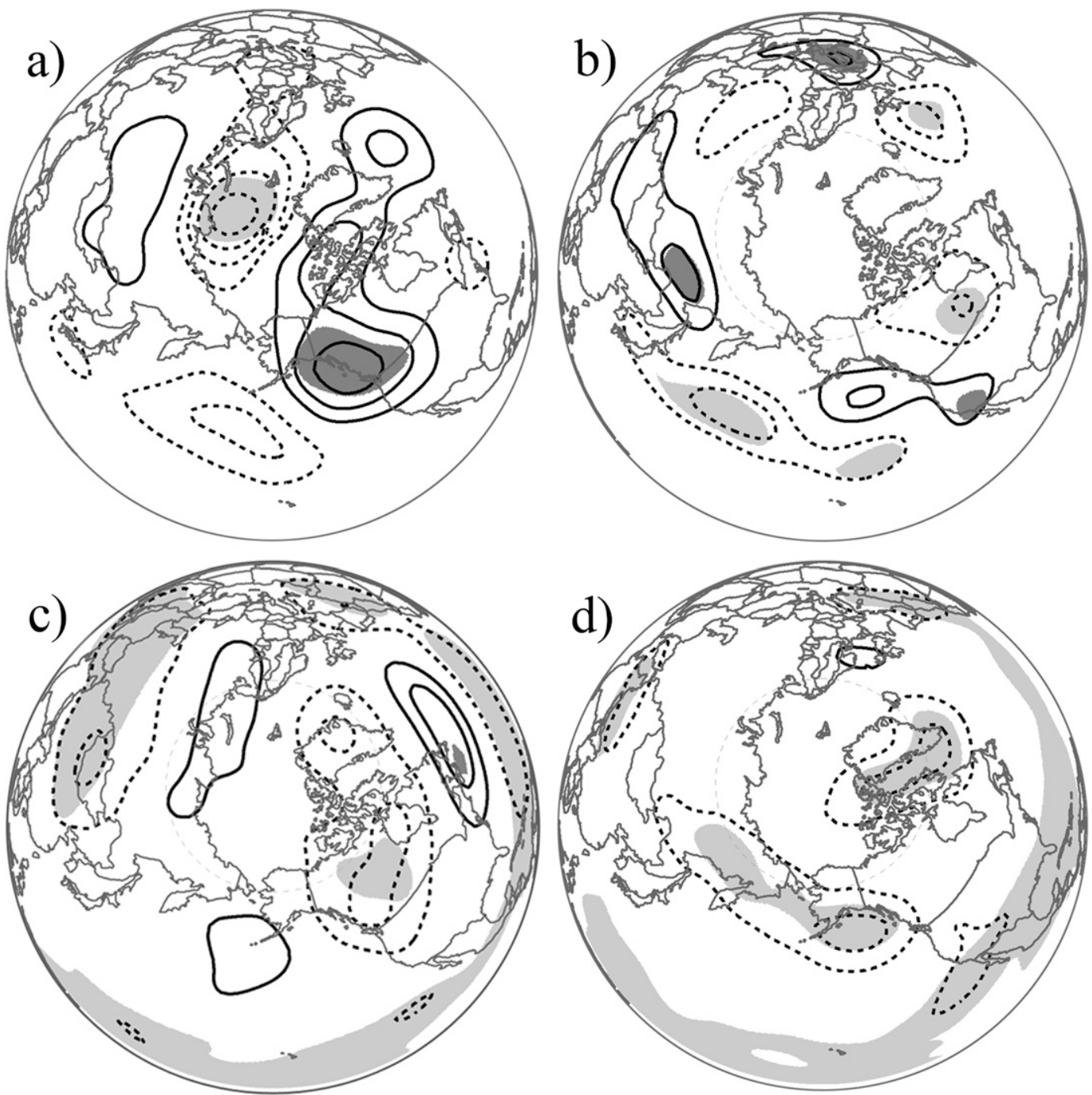

FIG. 7. Average 500-hPa geopotential height anomalies for the (a) five highest accumulation cold seasons, (b) four highest accumulation warm seasons, (c) six lowest accumulation cold seasons, and (d) six lowest accumulation warm seasons. Height anomalies are contoured in intervals of $10 \mathrm{~m}$, beginning at $+10 \mathrm{~m}$ (solid, positive) and $-10 \mathrm{~m}$ (dashed, negative). Anomalies greater (less) than the 95th (5th) percentile in a Monte Carlo analysis are shaded dark (light) gray.

These results are notably higher than those from the same analysis performed solely on Eclipse core $1(\sim 5 \%-10 \%$; Wake et al. 2002). Both comparisons contribute to a growing body of evidence that supports stacking multiple proxy records improves the climate signal-to-noise ratio (Fisher et al. 1996; White et al. 1997; Kreutz et al. 2004).

To test the sensitivity of the seasonal divisions to the robustness of the composites, two new seasonal time series of accumulation and isotope ratios were calculated by shifting the seasonal divisions by \pm 1 month (September-February/March-August and NovemberApril/May-October). On average, these two variations had a lower percentage of seasons of consistent anomaly patterns. The only exceptions were low accumulation for September-February, and most fractionated isotopes for May-October and March-August.

\section{Discussion}

Based on our analysis, 6-month seasons of extreme accumulation and extreme isotope values at Eclipse are sometimes associated with large-scale atmospheric circulation patterns that will be useful for climate reconstruction of the North Pacific region. Table 3 summarizes the fraction of the 4-6 seasons in each of the 

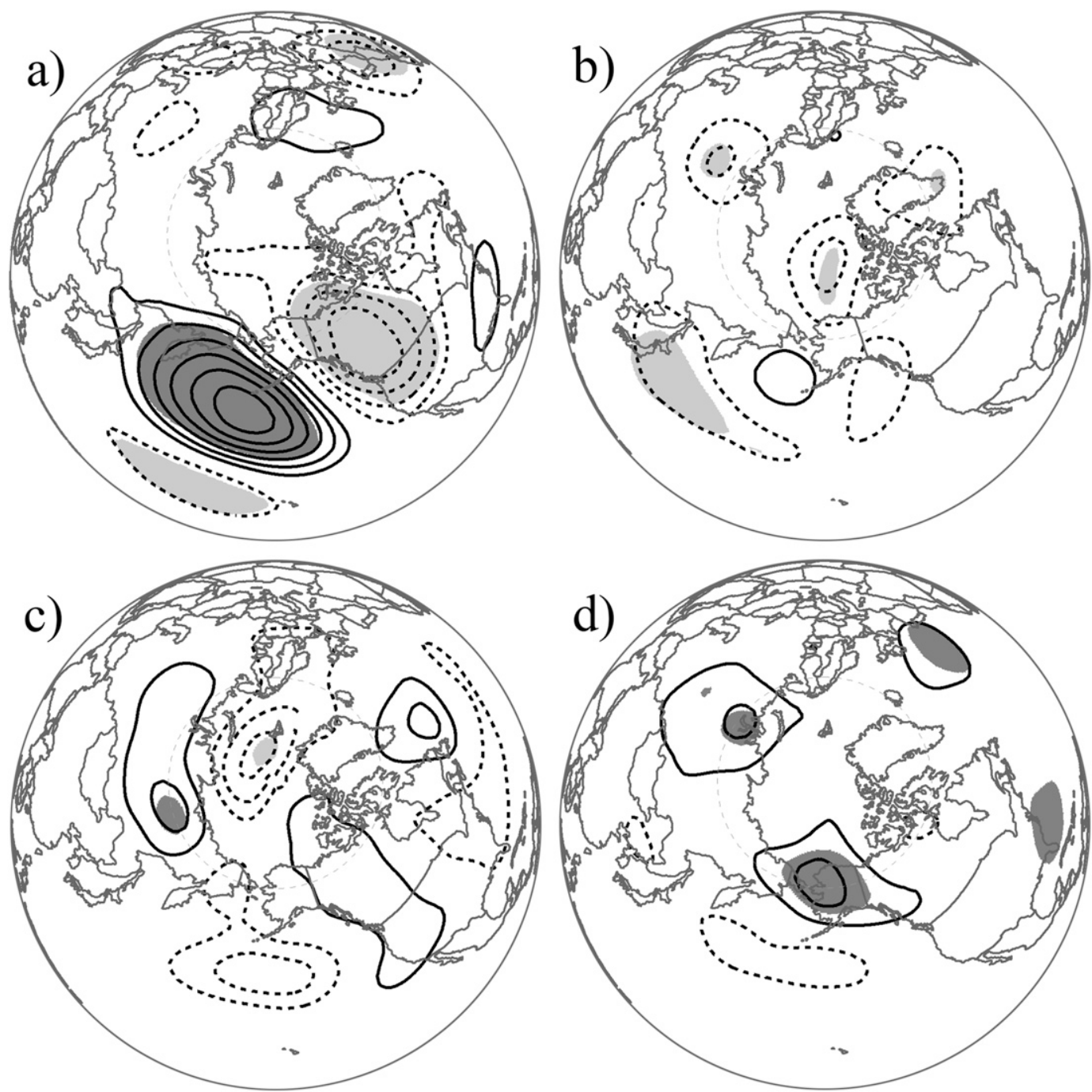

FIG. 8. Average 500-hPa geopotential height anomalies for the (a) five most fractionated isotopes cold seasons, (b) six most fractionated isotopes warm seasons, (c) six least fractionated isotopes cold seasons, and (d) six least fractionated isotopes warm seasons. Height anomalies are contoured in intervals of $10 \mathrm{~m}$, beginning at $+10 \mathrm{~m}$ (solid, positive) and $-10 \mathrm{~m}$ (dashed, negative). Anomalies greater (less) than the 95th (5th) percentile in a Monte Carlo analysis are shaded dark (light) gray.

respective eight groups that exhibited a pattern similar to the 500-hPa geopotential height composite anomaly patterns. The second pair of numbers in parentheses indicates that including additional extreme proxy seasons (i.e., beyond the initial 4-6) maintains or increases the percentage of seasons that match the composite pattern for two of the eight groups (cold-season least fractionated isotopes and warm-season most fractionated isotopes). The cold seasons of both extremes of isotopes and accumulation are associated with the most consistent height anomaly patterns (i.e., $67 \%-100 \%$ of the extreme proxy cold seasons match the composite pattern) and have the best potential to be high fidelity proxies for 500 -hPa geopotential height patterns in the North Pacific region over the last $\sim 500$ years. With the exception of most-fractionated isotopes, the warm season extreme proxy values are not associated with consistent atmospheric circulation patterns.

The height anomaly composites for the highest accumulation and least fractionated isotopes cold-season composites both show a positive PNA tripole pattern from the subtropical Pacific to western North America. This positive PNA pattern acted to increase southerly flow from a moisture source into the St. Elias Mountains thereby providing a mechanism for increased accumulation and potentially less fractionated isotopes. The second eigenmode of precipitation (Fig. 4b), with positive 
TABLE 3. The number preceding the shill is the number of seasons showing $500-\mathrm{hPa}$ geopotential height anomalies of the most common pattern for that group. The number following the shill is the number of seasons used in the respective group for the 19482001 period. For some groups, expanding the groups to include more extreme proxy seasons maintains or increases the value of the fraction and is shown in parentheses for those groups. Boldface indicates the groups associated with the most consistent anomaly patterns $(\geq 80 \%)$.

\begin{tabular}{lcc}
\hline \hline \multicolumn{1}{c}{ Ice core records } & Cold season & Warm season \\
\hline High accumulation & $\mathbf{4 / 5}$ & $2 / 4$ \\
Low accumulation & $4 / 6$ & $\mathbf{1 / 6}$ \\
Most-fractionated $\delta$ & $\mathbf{5 / 5}$ & $4 / 6(6 / 9)$ \\
Least-fractionated $\delta$ & $4 / 6(\mathbf{8} / \mathbf{1 0})$ & $2 / 6$ \\
\hline
\end{tabular}

precipitation anomalies focused along the southern Alaskan coast, and the first eigenmode of temperature (Fig. 5), with warm temperature anomalies in northwestern North America, are consistent with a positive PNA pattern (Trenberth et al. 1998; Rodionov et al. 2007). The statistically significant EOF-proxy correlations and robust height anomaly composite patterns support that Eclipse preserves a regional record of climate variability.

The opposite pattern occurred for the low accumulation and most fractionated cold-season groups. This pattern is associated with a flatter trough-ridge pattern and weaker and/or fewer cyclones to deposit snow across the St. Elias Mountains. With small-amplitude short waves bringing snowfall to Eclipse, winds associated with these systems would draw upon moisture from a source to the west or southwest. Sea surface temperatures decrease from east to west in the North Pacific, implying a colder, more fractionated isotope moisture source that can be a source of the more fractionated isotopes in the Eclipse ice cores suggesting stable isotopes may be an indicator of moisture source region (Merlivat and Jouzel 1979; Johnsen et al. 1989). Colder air masses with associated higher fractionated isotopes (Dansgaard 1964) would also occur with a westerly wind direction.

Eight out of the top 10 least fractionated isotopes and five of the top six high accumulation cold seasons were associated with SST patterns of a positive PDO and/or an El Niño. An El Niño occurred for five of the top nine least-fractionated isotopes cold seasons while a positive PDO occurred for 7 of the top 10. Of the three cold seasons in the top 10 least fractionated isotopes that had a positive PDO and not an El Niño, two seasons (1961, 1981) are in the top six of the high accumulation group (the other, 2001, only has proxy data from core 3 ). Taken together, these data suggest positive SST anomalies in the eastern tropical Pacific during an El Niño interact with the atmosphere to produce positive PNA patterns that result in less-negative values of isotopes to Eclipse, but not extremely high accumulation, while SST in a positive PDO pattern cause positive PNA patterns that result in high accumulation at Eclipse, but not extremely low fractionated isotopes. The different forcing mechanisms of each-El Niño-related convection driving the upper-tropospheric dynamical cause of the former (e.g., Rasmussen and Wallace 1983) and the lowertropospheric atmosphere-ocean coupling driving the latter-may explain why high isotopes and accumulation do not occur during the same seasons regularly. We speculate that the enhanced SST gradient south of Alaska associated with a positive PDO [ 2K $\left.(1000 \mathrm{~km})^{-1}\right]$ causes increased low-level baroclinicity that 1) fuels stronger or more cyclones that deposit more snow at Eclipse and/or 2) shifts the mean tracks of cyclones to be more favorable to deposit snow at Eclipse. Evidence that supports case 2 is seen in observational and numerical modeling studies that show the PDO modulates the spatial teleconnections of ENSO (e.g., Gershunov and Barnett 1998; Yu and Zwiers 2007). A general reversal of these height and SST anomalies occurred for the low accumulation and most fractionated isotopes cold seasons that were associated with a negative PNA pattern. All top eight most fractionated isotopes and six of the top seven lowest accumulation cold seasons were associated with a negative PDO. Very few seasons between the two groups match, but over half of the top 10 seasons of both groups were associated with a La Niña suggesting La Niña-PDO interactions may not be the reason for the different seasons in the low accumulation and low stable isotopes groups.

All lowest accumulation seasons occurred prior to 1977 and most highest accumulation seasons occurred after 1977, the year that the multidecadal period of the PDO switched from a negative to a positive phase. At this time, temperature across Alaska increased abruptly by $1^{\circ} \mathrm{C}$ and annual precipitation increased approximately $20 \%$ into the 1980s and 1990s (Shulski and Wendler 2007). This association suggests multidecadal modes of North Pacific SST variability cause an imbalance in the probability of Eclipse receiving high or low seasonal accumulation.

For the warm season, only the most fractionated isotopes group showed modest consistency in its patterns ( $\sim 67 \%$ ) exhibiting 500 -hPa geopotential height anomalies that caused a deamplified trough-ridge pattern. The composite (Fig. 8b) is similar to the leading mode of summer (JJA) 200-hPa geopotential height characterized by a stronger North Pacific anticyclone and cooler surface air temperatures in southern Alaska and Yukon (Lau et al. 2004). A physical model similar to the coldseason most-fractionated isotopes may also apply here. The similarity of patterns for both cold- and warm-season most fractionated isotopes suggests a preferred pathway 
and, potentially, singular mode for highly fractionated isotopes to reach Eclipse. For the warm-season groups in general, multiple phenomena, such as convection and cutoff lows that may not have statistically significant synoptic-scale height anomalies, may contribute to high accumulation during the warm season.

The results shown here, calculated by isolating the most extreme seasons of isotopes and accumulation, add to other studies using the same general method that also reveal nonlinearities with the high and low extremes. Rupper et al. (2004) also found a strong positive PNA signal in the high accumulation years at nearby Mt. Logan, but no consistent signal for low accumulation years. Moore et al. (2002) made a composite of 250-hPa geopotential height of the difference between the top and bottom five accumulation years between 1948-87 at Mt. Logan and found circulation patterns resembling the PNA during anomalous accumulation years similar to Eclipse. These strong associations from multiple studies support the methodology of choosing only the extreme years or seasons of accumulation and isotopes from ice cores in the Saint Elias Range and possibly elsewhere. Meanwhile, intermediate values may result from a more balanced mix of these oceanic and atmospheric patterns and/or other patterns and phenomena that offset each other and produce weak composite anomalies. Or, they may result from variability in the strength and location of the PNA centers of action that result in variability of storm tracks, preferred precipitation pathways, and therefore, the amount of precipitation and fractionation of isotopes received at any specific location.

To further test the aforementioned idea that isotope ratios vary with source region, a traditional analysis of deuterium excess $(d)$ was performed (Merlivat and Jouzel 1979; Johnsen et al. 1989; Fisher et al. 2004). Sections of core 2 (1936-69) and core 3 (1912-2001) were sampled for both $\delta^{18} \mathrm{O}$ and $\delta \mathrm{D}$. Over their common interval (1936-69), they correlated weakly and negatively for both the cold $(-0.17)$ and warm $(-0.15)$ seasons. Composites of $500-\mathrm{hPa}$ geopotential height anomalies for the top and bottom five $d$ seasons of each core's respective time period revealed weaker meridional flow for three of the four groups, with the top five cold seasons in core 2 featuring a positive height anomaly just south of Eclipse. These results indicate $d$ does not appear to be a consistent proxy for moisture source region at Eclipse, which agrees with the conclusions by Fisher et al. (2004) that $d$ indicates moisture source only in higher elevations in the St. Elias Mountains (e.g., Mt. Logan), and the atmospheric model of variable isotope layers posited by Holdsworth et al. (2002); Holdsworth 2008). Rather, $\delta \mathrm{D}$ and $\delta^{18} \mathrm{O}$ are reliable indicators of atmospheric circulation patterns, and possibly, moisture source region via these patterns.

While a more persistent or stronger meridional pattern appears responsible for most high accumulation cold seasons, the cold season with the highest accumulation $(1962 ; 91 \mathrm{~cm})$ was associated with the converse pattern-a flatter Rossby wave. We ran several analyses to determine the cause of this outlier. Meteorologically, an analysis of Hovmöller diagrams of 4-times-daily 500-hPa geopotential height and SLP of multiple years, including 1962, do not suggest any unusually powerful cyclones or significantly higher frequency of cyclones. Stations from the Cook Inlet to the Alaskan panhandle and northward to the Alaska Range all experienced near or slightly above average precipitation in each year from 1961-63, which supports categorically high accumulation. The beta activity and Cs-137 peaks in 1962 from nuclear activity ensures that this year is dated accurately (see Fig. 2 in Wake et al. (2002) for a beta activity time series). All three cores had above average accumulation, with core 3 having its highest cold season accumulation $(110 \mathrm{~cm})$. Although we cannot completely rule out unusual meteorological phenomena, we conclude the most likely cause for the 1962 outlier is a subseasonal dating offset that permitted the inclusion of accumulation from the previous and/or subsequent warm seasons to cause an above average accumulation cold season to appear exceptional.

\section{Conclusions}

This detailed analysis of the Eclipse stacked accumulation and stable isotope records quantified modern era relationships with climate indices, North Pacific SST, and regional atmospheric circulation patterns on a seasonal temporal scale. The most extreme ice core accumulation and extreme stable isotope values (up to $20 \%$ of the seasons in the 53 years of records examined) for the cold season from Eclipse are associated with consistent atmospheric circulation patterns. It is these extreme proxy cold seasons that have the highest potential for reconstruction of regional patterns, such as the PNA and the PDO. Specifically, the least-fractionated isotopes and high accumulation cold seasons are both associated with positive PDO and PNA patterns at $80 \%$ confidence. Although they share the same atmospheric pattern, the least fractionated isotopes and high accumulation cold seasons do not match. This could be caused by different ocean-atmosphere interactions associated with the two groups: anomalous equatorial Pacific convection inducing a dynamically driven positive PNA for least fractionated isotopes and North Pacific ocean-atmosphere coupling with an increased SST 
gradient inducing a positive PNA pattern conducive to higher accumulation. The opposite ocean and atmospheric patterns are associated with the most fractionated isotopes and the low accumulation cold seasons at $100 \%$ and $67 \%$ confidence, respectively. Of the four warm season groups, only the most fractionated isotope values were associated with a relatively consistent pattern (67\%), which was similar to the cold season most fractionated isotope composite pattern with a slight shift to the west. The characteristics of transient atmospheric features that comprise these mean seasonal $500-\mathrm{hPa}$ geopotential height patterns will be explored in future work.

Despite several high percentages, the consistency of atmospheric circulation patterns for each of the four cold-season proxy groups is $67 \%-100 \%$ and for the four warm seasons groups is $50 \%$ or less, except for the most fractionated isotopes warm season. Even the higher percentages imply that errors will occur in a reconstruction using these extreme proxy values. At best, we can expect to reconstruct up to one-fifth of the cold seasons at a high level of confidence $(>67 \%)$ if basic paleoclimate reconstruction assumptions are true. It will be beneficial to expand this analysis over a longer calibration period.

The composite patterns and stronger correlations between proxies and meteorological station data support the method of averaging multiple ice core records to generate a record with a stronger climate signal. The well-constrained depth-age scale, negligible amount of melt, and high accumulation rate give us high confidence in this calibration. We expect this Eclipse climate proxy calibration will allow extreme years of accumulation and stable isotopes to be used to reconstruct atmospheric circulation and SST patterns for approximately one-fifth of cold seasons, which will be explored in a future study.

Acknowledgments. The comments from three anonymous reviewers were very thoughtful, constructive, and appreciated. I am grateful for the discussions with and insight shared by Erich Osterberg, Jack Dibb, and Joe Licciardi. This work was supported by the National Science Foundation - Office of Polar Programs (Grant 0714004).

\section{REFERENCES}

Alley, R. B., and Coauthors, 1993: Abrupt increase in Greenland snow accumulation at the end of the Younger Dryas event. Nature, 362, 527-529.

Barnston, A. G., and R. E. Livezey, 1987: Classification, seasonality, and persistence of low-frequency atmospheric circulation patterns. Mon. Wea. Rev., 115, 1083-1126.

Biondi, F., A. Gershunov, and D. R. Cayan, 2001: North Pacific decadal climate variability. J. Climate, 14, 5-10.
Blake, E. W., C. P. Wake, and M. D. Gerasimoff, 1998: The ECLIPSE drill: A field-portable intermediate-depth ice-coring drill. J. Glaciol., 44, 175-178.

Cook, E. R., R. D. D'Arrigo, and M. E. Mann, 2002: A well-verified, multiproxy reconstruction of the winter North Atlantic oscillation index since A.D. 1400. J. Climate, 15, 1754-1764.

Crowley, T. J., and T. S. Lowery, 2000: How warm was the medieval warm period? Ambio, 29, 51-54.

Dansgaard, W., 1964: Stable isotopes in precipitation. Tellus, 16, 436-468.

, J. W. C. White, and S. J. Johnsen, 1989: The abrupt termination of the Younger Dryas climate event. Nature, 339, 532-534.

D'Arrigo, R., G. Wiles, G. Jacoby, and R. Villalba, 1999: North Pacific sea surface temperatures: Past variations from tree rings. Geophys. Res. Lett., 26, 2757-2760.

Fisher, D. A., and R. M. Koerner, 1994: Signal and noise in four icecore records from the Agassiz Ice Cap, Ellesmere Island, Canada: Details of the last millennium for stable isotopes, melt and solid conductivity. Holocene, 4, 113-120.

,-- K. Kuivinen, H. B. Clausen, S. J. Johnsen, J.-P. Steffensen, and N. Gunderstrup, 1996: Inter-comparison of ice core d18O and precipitation records from sites in Canada and Greenland over the last 3,500 years and over the last few centuries in detail using EOF techniques. Climate Variations and Forcing Mechanisms of the Last 2000 Years, R. S. Bradley, J. Jouzel, and P.D. Jones, Eds., Springer-Verlag, 297-330.

, and Coauthors, 2004: Stable isotope records from Mount Logan, Eclipse ice cores and nearby Jellybean Lake. Water cycle of the North Pacific over 2000 years and over five vertical kilometers: Sudden shifts and tropical connections. Geogr. Phys. Quat., 58, 337-352.

, and Coauthors, 2008: The Mt Logan Holocene-late Wisconsinan isotope record: Tropical Pacific-Yukon connections. Holocene, 18, 667-677.

Gershunov, A., and T. P. Barnett, 1998: Interdecadal modulation of ENSO teleconnections. Bull. Amer. Meteor. Soc., 79, 2715-2725.

Goto-Azuma, K., T. Shiraiwa, S. Matoba, T. Segawa, S. Kanamori, Y. Fujii, and T. Y. Yomasaki, 2003: An overview of the Japanese glaciological studies on Mt. Logan, Yukon Territory, Canada, in 2002. Bull. Glaciol. Res., 20, 65-72.

Hammer, C. U., H. B. Clausen, and H. Tauber, 1986: Ice-core dating of the Pleistocene/Holocene boundary applied to a calibration of the ${ }^{14} \mathrm{C}$ time scale. Radiocarbon, 28, 284-291.

Higgins, R. W., A. Leetmaa, Y. Xue, and A. Barnston, 2000: Dominant factors influencing the seasonal predictability of U.S. precipitation and surface air temperature. J. Climate, 13, 3994-4017.

Holdsworth, G. H., 2008: Interpreting $\mathrm{H}_{2} \mathrm{O}$ isotope variations in high-altitude ice cores using a cyclone model. J. Geophys. Res., 113, D08103, doi:10.1029/2007JD008639.

—, and H. R. Krouse, 2002: Altitudinal variation of the stable isotopes of snow in regions of high relief. J. Glaciol., 48, 31-41.

_ S. Fogarasi, and H. R. Krouse, 1991: Variation of the stable isotopes of water with altitude in the Saint Elias Mountains of Canada. J. Geophys. Res., 96 (D4), 7483-7494.

-, H. R. Krouse, and M. Nosal, 1992: Ice core climate signals from Mount Logan Yukon A.D. 1700-1987. Climate Since A.D. 1500, R. S. Bradley and P. D. Jones, Eds., Routledge, 483-504.

Johnsen, S. J., W. Dansgaard, and J. W. C. White, 1989: The origin of Arctic precipitation under present and glacial conditions. Tellus, 41B, 452-468. 
Kalnay, E., and Coauthors, 1996: The NCEP/NCAR 40-Year Reanalysis Project. Bull. Amer. Meteor. Soc., 77, 437-471.

Kaufman, D. S., Coauthors, 2009: Recent warming reverses longterm Arctic cooling. Science, 325, 1236-1239.

Kreutz, K. J., C. P. Wake, and K. Yalcin, 2004: Signal-to-noise ratios and climate records from the Eclipse Icefield ice cores. Eos, Trans. Amer. Geophys. Union, 85 (Fall Meeting Suppl.), Abstract PP21A-1346.

Lau, K.-M., J.-Y. Lee, K.-M. Kim, and I.-S. Kang, 2004: The North Pacific as a regulator of summertime climate over Eurasia and North America. J. Climate, 17, 819-833.

Mann, M. E., 2002: The value of multiple proxies. Science, 197, $1481-1482$.

, Z. Zhang, M. K. Hughes, R. S. Bradley, S. K. Miller, S. Rutherford, and F. Ni, 2008: Proxy-based reconstructions of hemispheric and global surface temperature variations over the past two millennia. Proc. Natl. Acad. Sci. USA, 105, $13252-13257$.

Mantua, N. J., S. R. Hare, Y. Zhang, J. M. Wallace, and R. C. Francis, 1997: A Pacific interdecadal climate oscillation with impacts on salmon production. Bull. Amer. Meteor. Soc., 78, 1069-1079.

Meeker, L. D., and P. A. Mayewski, 2002: A 1400-year high-resolution record of atmospheric circulation over the North Atlantic and Asia. Holocene, 12, 257-266.

Merlivat, L., and J. Jouzel, 1979: Global climatic interpretation of the deuterium-oxygen 18 relationship for precipitation. J. Geophys. Res., 84 (C8), 5029-5033.

Moore, G. W. K., G. Holdsworth, and K. Alverson, 2001: Extratropical response to ENSO as expressed in an ice core from the Saint Elias mountain range. Geophys. Res. Lett., 28, 34573460 .

, K. Alverson, and G. Holdsworth, 2002: Variability in the climate of the Pacific Ocean and North America as expressed in the Mount Logan ice core. Ann. Glaciol., 35, 423-429.

,$- \ldots$, and — 2003: The impact that elevation has on the ENSO signal in precipitation records from the Gulf of Alaska region. Climatic Change, 59, 101-121.

Osterberg, E., and Coauthors, 2008: Ice core record of rising lead pollution in the North Pacific atmosphere. Geophys. Res. Lett., 35, L05810, doi:10.1029/2007GL032680.

Rasmussen, E. M., and J. M. Wallace, 1983: Meteorological aspects of the El Nino/Southern Oscillation. Science, 222, 1195-1202.

Rodionov, S. N., N. A. Bond, and J. E. Overland, 2007: The Aleutian Low, storm tracks, and winter climate variability in the Bering Sea. Deep-Sea Res. II, 54, 2560-2577.

Rupper, S., E. J. Steig, and G. Roe, 2004: The relationship between snow accumulation at Mt. Logan, Yukon, Canada, and climate variability in the North Pacific. J. Climate, 17, 4724-4739.

Schmutz, C., J. Luterbacher, D. Gyalistras, E. Xopalki, and H. Wanner, 2000: Can we trust proxy-based NAO index reconstructions? Geophys. Res. Lett., 27, 1135-1138.

Shulski, M., and G. Wendler, 2007: The Climate of Alaska. University of Alaska Press, $216 \mathrm{pp}$

Thompson, D. W. J., and J. M. Wallace, 2001: Regional climate impacts of the Northern Hemisphere annular mode. Science, 293, 85-89.
Trenberth, K. E., 1997: The definition of El Niño. Bull. Amer. Meteor. Soc., 78, 2771-2777.

—, G. W. Branstator, D. Karoly, A. Kumar, N.-C. Lau, and C. Ropelewski, 1998: Progress during TOGA in understanding and modeling global teleconnections associated with tropical sea surface temperatures. J. Geophys. Res., 103 (C7), 14 291-14 324.

Urmann, D., 2009: Decadal scale climate variability during the last millennium as recorded by the Bona Churchill and Quelccaya ice cores. Ph.D. dissertation, Ohio State University, 281 pp.

Vega, A. J., K. G. Henderson, and R. V. Rohli, 1995: Comparison of monthly and intramonthly indicies for the Pacific/North American teleconnection pattern. J. Climate, 8, 2097-2103.

Wake, C., K. Yalcin, and N. S. Gundestrup, 2002: The climate signal recorded in the oxygen-isotope, accumulation and majorion series from the Eclipse ice core, Yukon Territory, Canada. Ann. Glaciol., 35, 416-422.

Wallace, J. M., and D. S. Gutzler, 1981: Teleconnections in the geopotential height field during the Northern Hemisphere Winter. Mon. Wea. Rev., 109, 784-812.

White, J. W. C., L. K. Barlow, D. Fisher, P. Grootes, J. Jouzel, S. J. Johnsen, M. Stuiver, and H. Clausen, 1997: The climate signal in the stable isotopes of snow from Summit, Greenland: Results of comparisons with modern climate observations. J. Geophys. Res., 102 (C12), 26 425-26 439.

Wilks, D. S., 2006: Statistical Methods in the Atmospheric Sciences. Academic Press, $627 \mathrm{pp}$.

Wolter, K., and M. S. Timlin, 1993: Monitoring ENSO in COADS with a seasonally adjusted principal component index. Proc. 17th Climate Diagnostics Workshop, Norman, OK, NOAA, $52-57$.

— and - 1998: Measuring the strength of ENSO eventsHow does 1997/98 rank? Weather, 53, 315-324.

Yalcin, K., and C. P. Wake, 2001: Anthropogenic signals recorded in an ice core from Eclispe Icefield, Yukon Territory, Canada. Geophys. Res. Lett., 28, 4487-4490.

,-- , and M. S. Germani, 2003: A 100-year record of North Pacific volcanism in an ice core from Eclipse Icefield, Yukon Territory, Canada. J. Geophys. Res., 108, 4012, doi:10.1029/ 2002JD002449.

,-- K. J. Kreutz, M. S. Germani, and S. I. Whitlow, 2006a: Ice core evidence for a second volcanic eruption around 1809 in the Northern Hemisphere. Geophys. Res. Lett., 33, L14706, doi:10.1029/2006GL026013.

$\longrightarrow,-,-$, and S. I. Whitlow, 2006b: Seasonal and spatial variability in snow chemistry at Eclipse Icefield, Yukon Territory, Canada. Ann. Glaciol., 43, 230-238.

,,,--- and $-2006 \mathrm{c}$ : A $1000-\mathrm{yr}$ record of forest fire activity from Eclipse Icefield, Yukon, Canada. Holocene, 16, 200-209.

,,--- M. S. Gemani, and S. I. Whitlow, 2007: Ice core paleovolcanic records from the St. Elias Mountains, Yukon, Canada. J. Geophys. Res., 112, D08102, doi:10.1029/2006JD007497.

Yu, B., and F. W. Zwiers, 2007: The impact of combined ENSO and PDO on the PNA climate: A 1000-year climate modeling study. Climate Dyn., 29, 837-851.

Zhang, Y., J. M. Wallace, and D. S. Battisti, 1997: ENSO-like interdecadal variability: 1900-93. J. Climate, 10, 1004-1020. 